\title{
desenvolvinento $\tilde{\mathrm{em}}_{\mathrm{em}}$ QUESTAOO
}

\section{TECNOLOGIAS SOCIAIS E AS FORMAS DE PRODUZIR E VIVER NA ALDEIA INDÍGENA GYRÓ}

http://dx.doi.org/10.21527/2237-6453.2021.56.11126

Recebido em: $12 / 7 / 2020$

Aceito em: 6/5/2021

Aline Mendonça dos Santos ${ }^{1}$, Matheus da Silva e Silva²

\section{RESUMO}

O artigo aqui apresentado objetiva refletir os modos de produzir e viver dos indígenas da etnia kaingang, considerando as práticas e saberes da coletividade da aldeia Gyró, localizada no interior rural do município de Pelotas, Rio Grande do Sul. As práticas e saberes indígenas são considerados aqui como tecnologias sociais que precisam ser resgatadas, ressignificadas e visibilizadas como estratégias contra-hegemônicas diante da lógica dominante. $\mathrm{O}$ estudo consistiu em uma pesquisa exploratória que combinou pesquisa bibliográfica, pesquisa documental e pesquisa empírica com perspectivas metodológicas participativas, como a observação participante. $O$ artigo está constituído por três seções: na primeira seção trataremos a questão indígena no Brasil a partir de um ponto de vista histórico e pós-colonial; na segunda realizamos uma abordagem sobre a importância da cosmologia kaingang para produção de tecnologias sociais e na terceira e última seção trouxemos alguns resultados da pesquisa refletindo sobre os limites e desafios dos indígenas kaingangs em garantir seus modos de produzir e viver no novo território.

Palavras-chave: colonização; questão indígena; tecnologias sociais; produzir e viver.

\section{SOCIAL TECHNOLOGIES AND THE WAYS TO PRODUCE AND LIVE IN THE INDIGENOUS VILLAGE GYRÓ}

\section{ABSTRACT:}

The article presented here aims to reflect the ways of producing and living of the indigenous Kaigang, considering the practices and knowledge of the collectivity of Gyró village, located in the rural interior of the county of Pelotas, Rio Grande do Sul. Indigenous practices and knowledge are considered here as social technologies that need to be rescue, resigned and visualized as strategies against hegemonic in the face of the dominant logic. The study consisted of an exploratory research that combined bibliographic research, documentary research and empirical research with participatory methodological perspectives such as participant observation. The article consists of three sections: in the first section we will deal with the indigenous issue in Brazil from a historical and post-colonial point of view; in the second section we conducted an approach on the importance of Kaigang cosmology for the production of social technologies and in the third and final section we brought some results of the research reflecting on the limits and challenges of the Kaigangs indigenous in ensuring their ways of producing and living in the new territory.

Keywords: colonization; indigenous issue; social technologies; produce and live.

\footnotetext{
${ }^{1}$ Autora correspondente. Universidade Católica de Pelotas (UCPel). Rua Gonçalves Chaves, 373 - Centro. Pelotas/RS, Brasil. CEP 96015-560. http://lattes.cnpq.br/4584658074250491. https://orcid.org/0000-0002-1902-0293. aline.santos@ucpel.edu.br

2 Universidade Católica de Pelotas (UCPel). Pelotas/RS, Brasil.
} 


\section{APRESENTAÇÃO}

O artigo aqui apresentado objetiva refletir os modos de produzir e viver dos indígenas da etnia kaingang, considerando as práticas e saberes da coletividade da aldeia Gyró, localizada no interior rural do município de Pelotas, Rio Grande do Sul.

Partindo do pressuposto de que as práticas e saberes indígenas configuram tecnologias sociais - tecnologias que "aliam saber popular, organização social e conhecimento técnico-científico" - que respeitam e valorizam a cultura e os conhecimentos populares/tradicionais/ancestrais, compreende-se os modos de produzir e viver da aldeia Gyró a partir de duas perspectivas principais que também fundamentam as tecnologias sociais: estratégia de desenvolvimento do território como forma de resistir à lógica dominante e direito de existir dos sujeitos que vivem na comunidade (SANTOS, A. M. dos, 2017, p. 264).

O debate sobre a reforma agrária e a demarcação de terras indígenas, pautada pelos movimentos sociais, passa pelo reconhecimento dos modos de vida tradicionais. Compreende políticas essenciais de desenvolvimento justo, popular, solidário e sustentável, pressupondo mudança na estrutura fundiária, democratização do acesso à terra, respeito aos territórios e garantia da reprodução social dos povos do campo, das águas e das florestas. Nessa perspectiva, o processo compreende um sentido econômico e social quem consiste na necessidade de desconcentrar terra e na garantia de terra para quem tem potencial para cultivá-la, trabalhar, viver com sua família, fazendo garantir a função social reconhecida constitucionalmente como um bem da natureza para a sociedade (SANTOS; RIBEIRO, 2020).

No caso dos indígenas, o debate reflete duas situações diferentes: aqueles que historicamente lutam e resistem para produzir e viver na terra tradicional e aqueles que, por algum motivo, foram removidos das terras tradicionais e recomeçam seu processo de produzir e viver a partir de um outro território, seja no espaço rural ou urbano. ${ }^{3}$

No caso da aldeia Gyró estamos tratando da segunda situação. A história recente dos indígenas kaingangs em Pelotas inicia-se no ano 2015, quando uma família kaingang composta por 16 indígenas, migrou de Chapecó (Santa Catarina) e montou um acampamento às margens de uma avenida que comporta um tráfego intenso de veículos. Os kaingangs escolheram este espaço tendo em vista ser uma área que possui um canal (Santa Bárbara) e uma mata ciliar, pouco preservada. A expectativa era garantir as condições mínimas de subsistência, mas desse espaço só garantiam os cipós para a confecção do artesanato, pois a água do canal Santa Bárbara é poluída e não serve para o consumo humano e nem para pesca. Apesar das dificulda-

\footnotetext{
${ }^{3}$ Nos termos da legislação vigente (CF/88, Lei 6001/73 - Estatuto do Índio, Decreto n.⒈775/96), as terras indígenas podem ser classificadas nas seguintes modalidades: Terras Indígenas Tradicionalmente Ocupadas: São as terras indígenas de que trata o artigo 231 da Constituição Federal de 1988, direito originário dos povos indígenas, cujo processo de demarcação é disciplinado pelo Decreto n.o 1.775/96; Reservas Indígenas: São terras doadas por terceiros, adquiridas ou desapropriadas pela União, que se destinam à posse permanente dos povos indígenas. São terras que também pertencem ao patrimônio da União, mas não se confundem com as terras de ocupação tradicional. Existem terras indígenas, no entanto, que foram reservadas pelos Estados-membros, principalmente durante a primeira metade do século 20, que são reconhecidas como de ocupação tradicional; Terras Dominiais: São as terras de propriedade das comunidades indígenas, havidas, por qualquer das formas de aquisição do domínio, nos termos da legislação civil; Interditadas: São áreas interditadas pela Funai para proteção dos povos e grupos indígenas isolados, com o estabelecimento de restrição de ingresso e trânsito de terceiros na área. A interdição da área pode ser realizada concomitantemente ou não com o processo de demarcação, disciplinado pelo Decreto n. 1.775/96.
} 
des, o acampamento era considerado estratégico para os indígenas, por conta da localização e consequente garantia de comercialização dos seus artesanatos. Tratava-se de uma situação de grande vulnerabilidade social e isso despertou a atenção da comunidade de modo geral, das universidades, de entidades assistencialistas, bem como do poder público. A partir do diálogo entre estes diferentes sujeitos políticos, realizaram-se algumas audiências públicas na Câmara de Vereadores, entrevistas nos meios de comunicação locais, debates nas universidades, etc., para discutir a questão dos indígenas em Pelotas e, na sequência, a prefeitura dessa cidade iniciou o processo de sua remoção para outro território, em uma área rural do município. Desse modo, foram apresentados pela prefeitura de Pelotas alguns lugares para o assentamento dos indígenas, observando-se que todas as opções ofertadas ficavam distantes do centro da cidade. Assim, os indígenas kaingangs assentaram a aldeia Gyró em um território localizado na colônia Santa Eulália, que possui cerca de sete hectares e fica 30 quilômetros do centro da cidade.

A decisão de mudar de território não é uma questão fácil para as comunidades indígenas que possuem uma relação diferenciada com a terra. "Para o Kaingang, a terra o fez nascer, isso porque, conforme seu mito de origem, os primeiros Kaingangs saíram da terra". (LAROQUE; SILVA, 2013, p. 255), no entanto forças das circunstâncias sociais e políticas se impõem sobre algumas comunidades e os indígenas acabam optando por migrar para outro espaço.

Instalada a Aldeia Gyró em um dos territórios rurais de Pelotas, e de certa forma, garantido o acesso à terra, os kaingangs passaram a ter outros desafios, como garantir os seus modos de produzir e viver, o acesso aos direitos sociais (educação, saúde, assistência...) e garantir as condições de acesso à cidade, entre outros.

Diante desta realidade, o trabalho que aqui apresentamos busca refletir sobre as práticas e saberes, as tecnologias sociais que os kaingangs da Aldeia Gyró dinamizam para manter os seus modos de vida diante das adversidades de reorganizar a vida em um novo território, bem como resistir às lógicas dominantes do modo de produção capitalista que silenciam e invisibilizam os povos tradicionais.

Este trabalho é resultado de uma pesquisa que utilizou uma abordagem qualitativa, envolvendo pesquisa bibliográfica, documental e empírica. No estudo empírico realizou-se observação participante ${ }^{4}$ acompanhando o cotidiano da aldeia, espaços de comercialização do artesanato, bem como alguns encontros políticos das lideranças kaingangs para discutir as condições de subsistência da Aldeia Gyró em Pelotas.

Assim, para dar conta desta reflexão, aqui se pretende abordar algumas questões e desafios relacionados à aplicação das tecnologias sociais tradicionais na aldeia Gyró como forma de garantir seus modos de produzir e viver no novo território. A primeira seção descreve a questão indígena na América Latina e no Brasil, diante de um histórico processo de opressão por parte do colonialismo e do capitalismo. A segunda reflete sobre as tecnologias sociais a partir dos modos de produzir e viver dos indígenas kaingangs. A terceira seção trata de uma análise sobre as práticas e saberes potencializados como tecnologias sociais na Aldeia Gyró.

\footnotetext{
${ }^{4}$ Definimos observação participante como um processo pelo qual um pesquisador coloca-se como observador de uma situação social, com a finalidade de realizar uma investigação científica. O observador, no caso, fica em relação direta com seus interlocutores no espaço social da pesquisa, na medida do possível, participando da vida social deles, no seu cenário cultural, mas com a finalidade de colher dados e compreender o contexto da pesquisa (MYNAIO, 2011, p. 70).
} 


\section{A QUESTÃO INDÍGENA NO BRASIL DESDE UM PONTO DE VISTA HISTÓRICO E PÓS-COLONIAL}

A história de silenciamento e invisibilidade das comunidades indígenas no Brasil refletem os efeitos perversos da colonização europeia sobre o território latino-americano, presente ainda hoje nos modos de intervenção estatal sobre populações autóctones em todas as periferias do capitalismo (FANON, 1968; CÉSAIRE, 1978; LANDER, 2005). No que se refere aos povos indígenas do Brasil, esta história é entendida como inexistente pelas classes dominantes. Reconhece-se que "[...] há séculos é reproduzido um lacônico senso comum, pelas oligarquias da sociedade brasileira, onde se esconde a real história do genocídio cometido aos povos indígenas do Brasil" (SILVA, 2017, p. 15).

Desde o ponto de vista das teorias pós-coloniais, compreende-se que a ação de extermínio de sociedades indígenas não cessou no Brasil contemporâneo. Supõe-se, com isso, que há complementaridade entre a negativa do direito à vida dos indígenas no período colonial, a consolidação da política de Estado neoliberal no Brasil e a permanente ausência de políticas sociais que protejam os direitos humanos destes povos. Nesta lógica, Fanon já declarava: “o colonialismo não é uma máquina de pensar, não é um corpo dotado de razão. É a violência em estado bruto [...]" (FANON, 1968, p. 46). Para além disso, o colonialismo se faz presente no imaginário das sociedades e a história colonial dos países periféricos e semiperiféricos influencia diretamente na organização social, política e econômica do contexto atual. Como afirma Santos (2001, p. 38), "o fim do colonialismo enquanto relação política não acarretou o fim do colonialismo enquanto relação social, enquanto mentalidade e forma de sociabilidade autoritária e discriminatória".

Desse modo, dentro da contemporânea política de Estado, compreende-se que as políticas públicas do governo brasileiro, originadas a partir do Serviço de Proteção ao Índio (SPI), em 1910, e com a Fundação Nacional do Índio (Funai), em 1967, vieram com o objetivo de tomar os territórios dos povos tradicionais, tutelar e educar os indígenas para servirem de mão de obra barata e contribuir com a expansão do modo de produção capitalista no Brasil. Tal situação continua ocorrendo, e com o aval do Estado brasileiro, uma vez que as terras indígenas são sistematicamente ocupadas e degradadas por corporações multinacionais, ligadas ao ramo da mineração e outros setores de produção capitalista. Nas palavras de Novaes, aprendemos que, "no século XX as gigantes corporações capitalistas monopolistas [...], assassinaram lideranças de movimentos sociais, roubaram terras, provocaram inúmeros desastres socioambientais, entre outras ações" (NOVAES, 2018, p. 41). Este cenário violento comprova que a permanência da política de Estado no Brasil está indo em contraponto aos direitos humanos dos povos tradicionais, apesar das garantias constitucionais dos direitos das sociedades indígenas.

"O Estado, diz-se, é o instrumento que permite à classe dominante exercer o seu domínio violento sobre as classes dominadas" (CLASTRES, 1979, p. 197). Nesse contexto, o Estado brasileiro vem contribuindo para a destruição dos territórios indígenas, considerando a invasão desses territórios, pelo capital financeiro, mediante o apoio estatal.

Após 30 anos da promulgação da Carta Constitucional de 1988, que trata da garantia dos direitos indígenas sobre o seu território tradicional, seus conhecimentos populares e sua forma de viver, a sociedade brasileira pouco avançou na efetivação desses direitos constitucionais. Segundo alguns autores (ROSA, 2016; NOVAES, 2018), atualmente a expansão do capitalismo 
por intermédio do agronegócio, das grandes mineradoras, das usinas hidrelétricas, etc., está ocasionando um processo de deslocamento das aldeias indígenas para as periferias das cidades - como aconteceu em Altamira, no Estado do Pará (ROSA, 2016) na fase de construção da usina hidrelétrica de Belo Monte na curva grande do Rio Xingu.

Essa expansão do capitalismo sobre as terras indígenas obriga que os grupos indígenas, quando não removidos para as periferias das cidades, organizem seus acampamentos em pequenas reservas, às margens das rodovias. Esse processo ocasiona situações de remoção, que provavelmente são agravadas quando os indígenas resistentes a esse processo de invasão territorial são violentamente atacados e ameaçados. Presume-se que esse método neocolonial de controle, remoção, desapropriação e aldeamento dos povos indígenas, possa resultar na ameaça e, em alguns casos, na perda dos conhecimentos ancestrais e singulares dos povos originários, pois, como sinalizam Veronese e Ferrarini:

O colonialismo e seus desdobramentos em modos neocolonialista de dominação significaram a violenta ocupação de territórios, dizimação de povos e de seus sistemas locais de produção, mas também o epistemicídio de suas culturas, saberes e práticas (2017, p. 231).

A Aldeia Gyró não está fora deste processo violento de invasão de suas terras, como fica evidente na trajetória deste coletivo. Composto por um grupo de indígenas vindos do município de Chapecó, Estado de Santa Catarina, os membros da referida aldeia decidiram abandonar seu território, devido aos desentendimentos internos na aldeia onde o grupo residia, ocasionados pelo arrendamento de terras indígenas para a expansão do agronegócio, culminando, assim, na migração de parte da aldeia para Pelotas (SILVA, 2017).

Cabe destacar, ainda, que este processo de reorganização dos indígenas em um novo território de Pelotas dialoga com uma outra questão latente: o direito à cidade. As formas de organização das cidades brasileiras mercantilizam o espaço e segregam a maior parte da população em suas periferias. Milton Santos (2006), Roberto DaMatta (1997) e Ermínia Maricato (2014) vêm denunciando as investidas do capital financeiro sobre o território brasileiro. Trata-se de um contexto de expansão do capitalismo que atinge os territórios indígenas e conta com o incentivo do Estado brasileiro. Segundo Maricato (2014, p. 97), "O que restava de território ainda não subsumido à atividade propriamente capitalista até 30 anos atrás está em franco processo de incorporação

\section{O colonialismo e o capitalismo como formas de opressão}

A criação do Estado-nação e a normatização do Direito ocidental foram determinantes no processo racista de colonização, genocídio e segregação social dos povos ameríndios. Há muito autores como Fanon (1968), Césaire (1978) e Porto-Gonçalves revelam que "o colonialismo constituiu os estados territoriais moderno-coloniais em todo lugar" (PORTO GONÇALVES, 2018, p. 344).

No âmbito da América Latina, Quijano defende a reflexão de que o processo bárbaro de colonização do continente consolidou a efetivação do capitalismo mundial.

Só com a América pôde o capital consolidar-se e obter predominância mundial, tornando-se precisamente o eixo em torno do qual todas as demais formas foram articuladas para os fins do mercado mundial. Somente desse modo o capital transformou-se no de produção dominante (QUIJANO, 2005, p. 126). 
O modo de produção capitalista, com seus desdobramentos neoliberais, compreende o paradigma econômico e hegemônico da América Latina que vem ocasionando uma devastação ao meio ambiente, atingindo os territórios indígenas e desrespeitando os direitos humanos dos povos tradicionais.

Diante do modelo econômico e societário excludente e de um projeto civilizatório eurocêntrico, deparamo-nos com um processo de marginalização dos povos indígenas no continente americano. Conforme expõe Lander:

Os diferentes recursos históricos (evangelização, civilização, o fardo do homem branco, modernização, desenvolvimento, globalização) têm todos como sustento a concepção de que há padrão civilizatório que é simultaneamente superior e normal (2005, p. 14).

A colonização das Américas, além de dispor do caráter religioso, que foi empregado como modo de "dominação" dos corpos indígenas, também dispôs do racismo sistemático, classificando os coletivos ameríndios como uma raça inferior ao colono branco. Em tese, isso permitiu ao colono "domesticar" os corpos indígenas para o trabalho extrativista e também "dominar" as relações de trabalho nas colônias, pois, conforme situa Aníbal Quijano: "Na América, a ideia de raça foi uma maneira de outorgar legitimidade às relações de dominação impostas pela conquista" (QUIJANO, 2005, p. 118).

Assim, por meio das guerras coloniais ${ }^{5}$ e a conquista de parte dos territórios ameríndios, os europeus começam o processo extrativista das Américas; aos poucos a instalação das empresas coloniais extrativistas teve início, uma vez que, logo na chegada, os europeus encontraram os metais preciosos (o ouro e a prata) que adornavam os corpos indígenas e identificaram a necessidade de explorar os territórios a fim de encontrar mais riquezas.

Segundo revela Caio Prado Junior:

Os espanhóis [...] toparam desde logo nas áreas que lhes couberam com os metais preciosos, a prata e o ouro do México e do Peru. Mas os metais, incentivo e base suficiente para o sucesso de qualquer empresa colonizadora, não ocupam na formação da América senão um lugar relativamente pequeno (PRADO JUNIOR, 2006, p. 17).

Desse modo, as empresas extrativistas, instaladas nas colônias da América, inicialmente foram organizadas em torno do extrativismo dos metais, como o ouro e a prata, no entanto perceberam ser insuficientes para a garantia do processo de colonização e, portanto, deram sequência ao extrativismo dos recursos naturais, como a pesca, a madeira e o comércio de pele de animais. Assim, além da extração da terra, consolidou-se um processo de exploração e violência contra os coletivos ameríndios por meio da imposição do trabalho escravo e servil.

Conforme a era da "modernidade" avançava no continente americano, junto cresciam os saques dos recursos naturais das Américas, extraídos por intermédio do trabalho servil dos coletivos ameríndios. Entre os recursos naturais, que serviam para manter o modo de produção capitalista funcionando, como sinaliza Eduardo Galeano (2009), somente a prata extraída da mina de Potosí, na Bolívia, alimentou o capitalismo na Europa por cerca de dois séculos. Assim,

\footnotetext{
${ }^{5}$ Segundo Achiles Mbembe, "as guerras coloniais são concebidas como a expressão de uma hostilidade absoluta que coloca o conquistador contra um inimigo absoluto. Todas as manifestações de guerra e hostilidade marginalizadas pelo imaginário legal europeu encontraram lugar para reemergir nas colônias" (MBEMBE, 2016, p. 134).
} 
o processo de colonização europeia das Américas trouxe ao continente americano a febril usura capitalista. Apesar das distinções entre as colonizações inglesa, espanhola e portuguesa, o produto final da ação colonial foi o extrativismo dos recursos naturais do continente americano.

Todo o processo inicial de povoamento e extração dos recursos naturais das colônias europeias na América esteve baseado essencialmente na violência epistêmica. Assim, os coletivos indígenas que habitavam o território americano tiveram os seus conhecimentos deslegitimados e foram vistos pelos colonizadores como selvagens, bárbaros ou como povos à espera da chegada da "modernidade". "Modernidade" que os colonizadores acreditavam que apresentariam com o desembarque nos territórios "descobertos" em 1492.

\section{Conforme sinaliza Dussel}

(...); os habitantes das novas terras descobertas não apareceram como Outros, mas como $\mathrm{Si}$ - mesmo a ser conquistados, colonizados, modernizados, civilizados, como "matéria" do ego moderno. E foi assim que os europeus (particularmente os ingleses) se transformaram [...], nos "missionários da civilização em todo o mundo (...)" (1993, p. 36).

O projeto civilizatório dos europeus nas Américas, portanto, tomou corpo em todo o território americano e o resultado da violência imposta pela "modernidade" foi sentido por quase todos os coletivos indígenas (os outros) das Américas, pois seus modos de vida não eram comparáveis com os egocentristas brancos europeus. Segundo Henrique Dussel, "O 'conquistador' é o primeiro homem moderno ativo, prático, que impõe sua 'individualidade' violenta a outras pessoas, ao Outro" (1993, p. 43).

A estratégia de dominar os corpos indígenas passou a ser essencial para a dominação hegemônica do sistema econômico mundial. Conforme sinaliza Henrique Dussel, "no tempo da acumulação originária do capitalismo mercantil, a corporalidade índia será imolada e transformada primeiramente em ouro e prata - valor morto da objetivação do "trabalho vivo" [...] do índio" (DUSSEL, 1993, p. 52). Com isso, a exploração do trabalho escravo e servil dos corpos indígenas e posteriormente dos corpos negros, propiciou aos países do centro europeu o controle hegemônico do modelo de produção capitalista. ${ }^{6}$ Modo de produção, que atingiria a sua eficácia, a partir desta violenta colonização europeia das Américas (QUIJANO, 2005).

Segundo Florestan Fernandes:

Em termos sociológicos, os fundamentos legais e políticos dessa dominação colonial exigiam uma ordem social em que os interesses das Coroas e dos colonizadores pudessem ser institucionalmente preservados, incrementados e reforçados, sem outras considerações. Isso foi conseguido pela transplantação dos padrões ibéricos da estrutura social, adaptados aos trabalhos forçados dos nativos ou à escravidão (de nativos, africanos ou mestiços) (1973, p. 13).

\footnotetext{
${ }^{6}$ Segundo Anibal Quijano, "essa colonialidade do controle do trabalho determinou a distribuição geográfica de cada uma das formas integradas no capitalismo mundial. Em outras palavras, determinou a geografia social do capitalismo: o capital, na relação social de controle do trabalho assalariado, era o eixo em torno do qual se articulavam todas as demais formas de controle do trabalho, de seus recursos e de seus produtos. Isso o tornava dominante sobre todas elas e dava caráter capitalista ao conjunto de tal estrutura de controle do trabalho. Mas ao mesmo tempo, essa relação social específica foi geograficamente concentrada na Europa sobretudo, e socialmente entre os europeus em todo o mundo do capitalismo. E nessa medida e dessa maneira, a Europa e o europeu se constituíram no centro do mundo capitalista" (2005, p. 120).
} 
Por meio da exploração do trabalho e da violência exercida contra os corpos indígenas, avança uma longa trajetória do colonialismo europeu nas Américas. Uma trajetória marcada por conquistas dos povos ameríndios e por divisões coloniais, entre raça colonizadora e "colonizada". Conforme Henrique Dussel, "o 'eu colonizo' o outro, a mulher, o homem vencido, numa erótica alienante, numa economia capitalista mercantil, continua a caminhada do 'eu conquisto' para o 'ego cogito' moderno" (1993, p. 53).

O cristianismo e a religião católica ocuparam uma posição estratégica e privilegiada no processo de colonização da América e na efetivação do projeto capitalista neste território. Logo, a fim de fortalecer o cristianismo mediante a imposição do poder religioso, os sacerdotes católicos, enviados às Américas, começaram o processo de docilização dos corpos indígenas. Corpos, que, adorando o Deus, cristão, possivelmente, esqueceriam os seus "bárbaros" costumes e cederiam à era da modernidade.

Ao mesmo tempo em que os ameríndios contribuíram para o desenvolvimento do modo de produção capitalista, eles experienciaram "ver" as suas organizações sociais e os seus cultos místicos serem suprimidos pela imposição colonialista de "modernidade". Conforme sinaliza Henrique Dussel: “(...) como a religião indígena é demoníaca, e a europeia divina, a primeira deve ser totalmente negada (...)” (1993, p. 60).

Negando os ritos ${ }^{7}$ religiosos dos coletivos ameríndios, o objetivo dos conquistadores era catequizar os indígenas e instituir o cristianismo, ${ }^{8}$ como a única religião possível de ser praticada nas colônias americanas. Tratou-se de um processo de violência epistêmica e cultural. Como sinaliza Castro (1992), no entanto, os corpos indígenas agiram como as esculturas feitas nas árvores de murta: ${ }^{9}$ quando os sacerdotes menos esperavam os dogmas cristãos eram esquecidos e os indígenas voltavam aos seus ritos tradicionais.

Apesar de todo processo de opressão e colonização, historicamente os indígenas resistem, mantendo suas tradições como alternativa a lógica dominante. Segundo Addor:

A construção de alternativas a esse modelo deverá ser baseada nos ensinamentos das diferentes práticas emancipatórias em desenvolvimento, na diversidade de luta que os povos vêm travando em vários países latino-americanos (2016, p. 43).

\section{AS TECNOLOGIAS SOCIAIS NO CONTEXTO DA ALDEIA KAINGANG}

As práticas e os saberes indígenas configuram-se como um processo de resistência dos povos originários diante do padrão societário. Esse processo de resistência está constituído me-

\footnotetext{
${ }^{7}$ Nas palavras de Rogério da Rosa, "através do rito, as principais concepções cosmológicas a respeito das energias manifestas e veladas do mundo-aqui e do mundo-outro são explicadas, recriadas e representadas" (2005, p. 85).

${ }^{8}$ Segundo Friedrich Nietzsche, "quanta realidade teve de ser denegrida e negada, quanta mentira teve de ser santificada, quanta consciência transtornada, quanto "Deus" sacrificado? Para se erigir um santuário, é preciso antes destruir um santuário: esta é a lei - mostra-me um caso em que ela não foi cumprida" (NIETZSCHE, 2009, p. 77).

${ }^{9}$ Segundo Viveiros de Castro, “(...) na literatura jesuítica sobre os índios brasileiros desde a chegada dos primeiros padres da Companhia em 1549: o gentio desse país - inicial e exemplar, os Tupinambás litorâneos - era muito difícil de converter. [...] os índios - para usarmos um símile vegetal menos europeu que a estátua de murta - eram como a mata que os agasalhava, sempre pronta a se refechar sobre os espaços precariamente conquistados pela cultura: eram como sua terra, enganosamente fértil, onde tudo parecia se poder plantar, mas onde nada brotava que não fosse sufocado incontinenti pelas ervas daninhas. Enfim: este gentio sem fé, sem lei e sem rei não oferecia um solo fértil" (CASTRO, 1992, p. 22).
} 
diante o desenvolvimento das tecnologias sociais. São tecnologias capazes de conservar os conhecimentos ancestrais indígenas e mesclá-los com a ciência "moderna" ocidental. Como lembram Veronese e Ferrarini:

Mesmo após o genocídio colonial, resistem algumas práticas e saberes. Se houvesse uma real interação entre os saberes produzidos pelas culturas de resistência, com mútuo enriquecimento - todas as culturas são incompletas e podem beneficiar-se da troca com outras culturas - ganho geral (2017, p. 249).

Aniquilar os conhecimentos originários dos povos indígenas e suas tecnologias sociais, como mencionado na seção anterior, é parte do componente ideológico, de um processo de produção que desconhece as relações humanas simplificando o comércio das mercadorias na troca do capital pelo produto. Como explicita Novaes (2010, p. 67): “(...) a ideologia do progresso promovida pela classe dominante dissimula as relações sociais nela contida e é um dos veículos para a perpetuação dos que estão no poder (...)". Nesse contexto, aparenta que os costumes tradicionais de produção e comércio das aldeias são intencionalmente extintos, obrigando os povos indígenas a se adaptarem às formas de comércio impostas pelos colonizadores.

Segundo o Instituto de Tecnologia Social, a categoria representa o "conjunto de técnicas, metodologias transformadoras, desenvolvidas e/ou aplicadas na interação com a população e apropriadas por ela, que representam soluções para inclusão social (...)" (ITS BRASIL, 2019). No caso deste trabalho, as tecnologias sociais são compreendidas tendo em vista as tecnologias tradicionais desenvolvidas pelos indígenas e mescladas com as tecnologias produzidas pelo conhecimento científico, externos, que fazem parte dos hábitos das aldeias. Ao se referir à capacidade dos indígenas de fazerem dialogar diferentes tecnologias, Anapuaka Tupinambá diz:

(...) na capacidade que esses povos tiveram de passar 2.500 anos resistindo e ao mesmo tempo se reinventando de todas as formas possíveis, apropriando-se de outras tecnologias para poder continuar resistindo ( 2018, p. 32).

Visibilizar as experiências que potencializam os saberes tradicionais, reconhecendo o direito ao território, mantendo e fomentando os costumes tradicionais e as tecnologias sociais consiste também em garantir a dignidade e os direitos humanos dos povos indígenas. $\mathrm{O}$ Estado brasileiro tem responsabilidade de garantir os direitos sociais e, consequentemente, a dignidade humana dos povos indígenas. Como determina o Decreto Federal no 169 da Organização Internacional do Trabalho - OIT - em seu artigo 3, "Os povos indígenas e tribais deverão gozar plenamente dos direitos humanos e liberdades fundamentais, sem obstáculos nem discriminação" (BRASIL, 2004).

Compreender e refletir sobre as tecnologias sociais das comunidades indígenas é também a realização de um exercício de sociologia das ausências, que segundo Boaventura de Sousa Santos trata-se de desenvolver uma sociologia dos saberes ausentes, dos saberes produzidos como não existentes pela epistemologia hegemônica (SANTOS, 2008).

Uma sociologia das ausências passa pelo reconhecimento de que não há um saber único universal, mas vários saberes, que precisam ser visibilizados e compreendidos como saberes válidos e estratégicos diante da lógica dominante. Como destaca Porto Gonçalves, "o que se critica aqui é a ideia de que há somente um pensamento universal, aquele produzido a partir de uma província específica do mundo, a Europa (...)" (2018, p. 338). 
Tanto no campo político como no campo epistêmico, o reconhecimento das experiências indígenas, expressas no modo de produzir e viver das aldeias, visibiliza seu potencial contra-hegemônico, pois como sinaliza Santos A. M. dos (2017),

(...), mesmo sem terem um impacto revolucionário imediato, ditas experiências constituem resistência e provocam impactos significativos, já que se orientam por valores contrários à lógica dominante, como igualdade, solidariedade, cuidado e respeito com o meio ambiente (p. 259).

A importância da cosmologia kaingang na produção de tecnologias sociais

Para estudar as tecnologias sociais dos povos originários é preciso compreendê-las também a partir da cosmologia ${ }^{10}$ indígena.

A concepção cosmológica e a organização social dos kaingangs contemplam uma divisão social do coletivo indígena kaingang entre duas metades: exogâmicas e complementares. Essas metades dividem os kaingangs em dois grupos: os Kamé e os Kainru - Krê. Ambos são originários dos irmãos gêmeos e heróis mitológicos kaingang Kaimé e Kainru e, simbolicamente, representados por meio da marca comprida (Kaimé ), ou da marca redonda (Kainru).

Conforme Sergio Baptista da Silva:

$\mathrm{Na}$ realidade, as patri metades Kaingang representam apenas um aspecto - o sociológico - de toda uma concepção dual do universo. Todos os seres, objetos e fenômenos naturais são divididos em duas categorias cosmológicas, uma ligada ao gêmeo ancestral Kamé , e a outra vinculada ao gêmeo ancestral Kainru. Principalmente, as metades são percebidas pelos Kaingang como cosmológicas, estando igualmente ligadas aos gêmeos civilizadores, os quais emprestam seus nomes a elas (SILVA, 2002, p. 190).

Deste modo, de acordo com sua marca, Kaimé ou Kainru, as pessoas, os fenômenos da natureza, as plantas, os animais e tudo que envolve a cosmologia kaingang têm características físicas diferenciadas.

Entre as tecnologias sociais potencializadas pela cosmologia indígena, destacam-se os remédios do mato. É da natureza, especificamente do mato, que os indígenas kaingang retiram uma diversidade de medicamentos capazes de combater as doenças que atingem tanto o corpo quanto o espírito. A elaboração dos remédios do mato, contudo, depende da sabedoria e trabaIho dos Xamãs Kaingang. ${ }^{11}$ São estes que possuem os conhecimentos específicos de como manipular as ervas e obterem esses remédios. Conforme revela Rosa, "o remédio do mato que o kujà coleta na floresta é uma planta que nasce sozinha na mata fechada, protegida dos raios de sol, da intervenção direta do olhar e da mão humana" (ROSA, 2014, p. 89).

\footnotetext{
${ }^{10} \mathrm{As} \mathrm{cosmologias} \mathrm{indígenas} \mathrm{representam} \mathrm{modelos} \mathrm{complexos} \mathrm{que} \mathrm{expressam} \mathrm{suas} \mathrm{concepções} \mathrm{a} \mathrm{respeito} \mathrm{da} \mathrm{origem}$ do Universo e de todas as coisas que existem no mundo. Disponível em: <http://www.museudoindio.gov.br/educativo/pesquisa-escolar/245-mito-e-cosmologia> acesso em: 13 mar. 2018.

${ }^{11}$ Segundo Rogério Reus Gonçalves Rosa, "Esse profissional da saúde tem como seu parceiro uma diversidade de jagrẽ (espíritos auxiliares) que assumem tanto a forma não humana como a humana: o espírito animal da floresta (por exemplo, jaguatirica, gavião, coruja, cachorro), o espírito vegetal da floresta (taquara, árvore e cacique das matas), a água (espírito água da floresta e água santa) e o santo do panteão do catolicismo popular (Nossa Senhora Aparecida, Santo Antônio e São João Maria)" (ROSA, 2014, p. 86).
} 
Além dos remédios do mato, os indígenas kaingang também retiram o carvão das árvores $^{12}$ que, após queimadas, servem para as pinturas corporais utilizadas como proteção durante o ritual do Kiki. O mato também apresenta uma importância expressiva para as parteiras kaingang, que extraem da natureza as plantas que serão oferecidas às mulheres com a finalidade que tenham um parto natural e tranquilo. ${ }^{13}$

Na natureza os kaingangs obtêm as caças, os peixes, as plantas, as frutas e as raízes que culturalmente são utilizadas como alimentos. Do meio ambiente vêm, também, os cipós, as taquaras, sementes, etc., que servem de matéria-prima para a confecção dos artesanatos, os quais são a principal fonte de renda das famílias kaingang na atualidade. Assim, este cenário de integração dos indígenas kaingang com a natureza aponta a necessidade de que o meio ambiente esteja preservado e seja espaço adequado de exploração dos kaingang nos novos territórios.

\section{OS DESAFIOS DE PRODUZIR E VIVER DOS INDÍGENAS KAINGANGS NA ALDEIA GYRÓ}

Na Aldeia Gyró os desafios para dinamizar os modos de produzir e viver tradicionais dos kaingangs são muitos, uma vez que além do processo de resistência de suas práticas e saberes perante as imposições capitalistas, há o fato de que os indígenas na Aldeia Gyró não estão no território originário, estão explorando um novo local que nem sempre responde às necessidades tradicionais.

\section{Sobre as dificuldades de viver no novo território}

No que diz respeito aos desafios de viver no novo território, os indígenas destacam muitas questões, uma vez que, não tendo um território adequado para o atendimento de suas necessidades de produção e, consequentemente, de subsistência, precisam de uma atenção maior por parte do Estado na garantia dos mínimos direitos sociais. Desta forma, os indígenas alegam ter dificuldades de deslocamento, saúde, alimentação e educação, como descrevemos a seguir.

A dificuldade de deslocamento ao centro se dá no difícil acesso ao transporte público, pois a distância da Aldeia até a parada de ônibus mais próxima é de cerca de três quilômetros, distância que os kaingang percorrem a pé, carregando os artesanatos para comercializar no centro de Pelotas. Além disso, eles precisam pagar a passagem e nem sempre têm condições para tal.

Em relação à saúde, as dificuldades se expressam: 1) acesso aos serviços de pronto atendimento médico das ambulâncias do Serviço de Atendimento Móvel de Urgência (Samu), pois devido à distância do centro da cidade o atendimento é demorado. Houve a situação de uma indígena que entrou em trabalho de parto e, sem condições de extrair da natureza as plantas que as parteiras kaingangs usam nestas situações para garantir um parto natural, foi preciso chamar

\footnotetext{
${ }^{12}$ Segundo Fernandes e Piovezana, "com as cinzas do nó-de-pinho é confeccionada a tinta que serve para fazer a pintura facial nos indivíduos pertencentes à metade Kamé, presentes à beira do fogo (os indivíduos Kairu são pintados com cinzas de 'sete sangrias', um arbusto classificado como Kairu" $(2015$, p. 124)

${ }^{13}$ Segundo Freitas e Rokàg, "o tratamento com ervas do mato e do campo, indicado pela parteira, atua no corpo da mãe antes e após o parto. Do mesmo modo que os kujàe curandores, as parteiras também têm seu próprio repertório de conhecimentos acerca do ecossistema da floresta" (2007, p. 219).
} 
- Samu, no entanto a criança nasceu em condições adversas, nos braços do cacique antes da chegada da ambulância na Aldeia Gyró; 2) A Aldeia conta com uma Unidade Básica de Saúde (UBS) instalada em uma pequena casa de alvenaria preexistente à chegada dos kaingang no território. No começo os atendimentos médicos aconteciam semanalmente, realizados na UBS, pois a médica não se deslocava até a Aldeia. Na última visita realizada na Aldeia, em novembro de 2019, as lideranças indígenas relataram que há mais de um mês não ocorriam os atendimentos médicos na UBS da Aldeia.

Sobre a alimentação, os indígenas contam com um apoio do Estado até que tenham condições de prover seu próprio alimento no território. Os indígenas kaingang, no entanto, disseram que as sacolas de alimentos distribuídas pelo Estado não estavam chegando até a Aldeia com a frequência esperada.

Os desafios de viver na Aldeia Gyró também se apresentam para os kaingang tendo em vista as questões relacionadas ao acesso à educação, devido: 1) à necessidade do deslocamento dos jovens kaingangs até as escolas das localidades próximas da Aldeia; 2) preconceito da educação formal para com os indígenas. Houve uma situação em que um dos jovens kaingang sentiu-se constrangido por parte dos colegas brancos e desistiu de frequentar a escola.

Existe entre os indígenas kaingangs o desejo de abrir uma escola no território da Aldeia Gyró. O prédio está pronto e os indígenas aguardam posição do Estado para realizar melhoria do espaço e remunerar um dos indígenas kaingang como professor bilíngue. Nessa escola os indígenas kaingangs pretendem manter suas tradições e de forma oral passar os conhecimentos ancestrais às crianças e jovens, através das histórias, místicas e realizar oficinas de artesanato.

Por fim, entre as dificuldades de se viver no território, há também escassez de água potável. A Aldeia Gyró conta somente com uma pequena sanga, que seca durante o verão. Os indígenas kaingangs necessitam do abastecimento de água por um caminhão-pipa que é disponibilizado pela prefeitura de Pelotas. Depois de muitas reivindicações, os indígenas conseguiram que o Estado perfurasse um poço artesiano no território, no entanto até o término desta pesquisa o poço ainda não abastecia a Aldeia, devido ao fato de estarem à espera da instalação de uma bomba hídrica.

\section{Sobre as tradições e os modos de produzir}

Apesar das dificuldades, os kaingangs vêm ressignificando seus costumes, suas tradições e saberes e criando as condições para manter seu modo de vida, pois a comunidade está organizada respeitando as tradições kaingang. $O$ cacique se constitui como a liderança principal na Aldeia Gyró, cercado do apoio de outras lideranças. Juntos negociam politicamente os seus direitos sociais com os brancos e com os Estado.

Conservando os costumes, na Aldeia Gyró os indígenas kaingang respeitam as tradições relacionadas à constituição das famílias. Os casamentos acontecem entre as metades exogâmicas e complementares Kaimé e Kainru.

Sobre a língua, os moradores da Gyró, além do Português, são falantes do dialeto kaingang e estimulam as crianças da Aldeia a falarem ambos. 
A respeito das crenças religiosas, o sincretismo religioso da Aldeia é composto pela religião evangélica, ${ }^{14}$ contando com um pastor kaingang que realiza os cultos. Apesar de manterem o respeito às tradições, muitas coisas mudaram e, por exemplo, não há um pajé na Aldeia Gyró. Apesar de não possuírem pajé, num evento realizado na Aldeia, chamado de Semana Cultural, foi cogitado pelo cacique a possibilidade de trazer o pajé de outro território até a Aldeia para participar dos ritos.

O cacique mantém os costumes tradicionais de utilizar os remédios do mato (constituídos de plantas silvestres). O cacique é conhecedor do benefício para a saúde de diversas espécies de plantas, das quais ele mesmo faz uso e recomenda, contudo não são todos os indígenas kaingangs da Aldeia Gyró que utilizam os remédios do mato.

Os indígenas kaingang conservam o diálogo sobre as crenças ancestrais. Entre os ritos que, segundo eles, influenciam no desenvolvimento de algumas habilidades humanas para as crianças, destacam-se alguns banhos e remédios, por exemplo, o banho numa bacia onde colocam uma espécie de peixe, o jundiá, peixe rápido e escorregadio. Para os kaingang este ritual pode deixar as crianças mais rápidas e ágeis.

No que diz respeito aos desafios de produzir no novo território, os indígenas da Aldeia Gyró dizem que o território é pequeno para manter os costumes tradicionais kaingangs como coletar, caçar e pescar, no entanto o território possibilita a criação de alguns animais domésticos (porcos, galinhas), bem como o plantio sazonal de pequenas lavouras de feijão, milho, mandioca, melancia, etc.

Entre as tradições (tecnologias sociais) preservadas na produção de alimentos, destacam-se algumas plantas (urtigas -fuá) que servem de alimento humano, mas que não são consumidas pelo homem branco. Nos fundos da Aldeia Gyró foi preservada uma pequena mata, que aos olhos do branco não representa nada, mas neste espaço o cacique colhe os remédios e algumas ervas que thes servem de alimento e medicamento.

Por meio de uma parceria estabelecida com a Empresa de Assistência Técnica e Extensão Rural do Estado do Rio Grande do Sul (Emater/RS), os indígenas tiveram acesso a diversas sementes. De forma tradicional os kaingangs cultivam milho, melancia, mandioca, feijão, etc.

O trabalho de plantio, produção e divisão dos alimentos na Aldeia, inicialmente ocorreu por meio do trabalho coletivo, porém atualmente o trabalho se constitui de maneira individual e cada família que trabalha na terra cultiva seus alimentos separadamente. A separação ocorreu devido a desentendimentos entre os kaingangs no trabalho de produção e divisão da colheita dos alimentos.

\footnotetext{
${ }^{14} \mathrm{~A}$ religião evangélica avançou por parte significativa das comunidades indígenas no Brasil, Segundo Severo, "O constante temor pelo fim do mundo, materializado entre outras coisas pelos elementos apontados acima (perda territorial, fim da floresta virgem, etc.), fez com que os kaingangs buscassem alternativas para a salvação. Como bem ressaltaram Veiga (2004) e Almeida (2004), o virar espírito nunca foi uma predileção da cosmologia kaingang, o morto muitas vezes era tido como um traidor que abandonou sua família (VEIGA, 2000), contudo, imaginar que após a morte seu espírito ficará vagando pela Terra sem destino também nunca foi uma boa ideia. Dessa maneira, a crença evangélica encontra entre os kaingangs um terreno profícuo para alicerçar suas bases, ali o kujã perdeu credibilidade pela perseguição colonial, os rituais não são mais operantes pela política de aculturação protagonizada pelo governo brasileiro, ou seja, as crenças encontram uma população que busca uma saída para esse cenário desesperador" (SEVERO, 2018, p. 59).
} 
As tecnologias sociais na produção de alimentos são hibridas. Os kaingang utilizam dos conhecimentos tradicionais juntamente com o apoio e assessoria técnica da Emater/RS para o cultivo. No que diz respeito aos conhecimentos tradicionais, tratam o cultivo dos alimentos culturalmente trazido pelos kaingangs, utilizam dos conhecimentos no trabalho de preparo do solo e plantio não mecanizado. A Emater propõe a distribuição de sementes, adubos e procura aplicar as tecnologias necessárias para o plantio de uma horta de alfaces, cenoura, tomate, etc.

Na Aldeia Gyró os kaingangs não conseguem manter os costumes de caçar e de pescar, pois não há açude ou rio no pequeno território reservado à Aldeia. Os indígenas mais jovens pescam fora do território da Aldeia Gyró, em alguns riachos que passam nas proximidades, mas a oferta de peixe é pequena. Há o interesse do cacique em construir um açude para criação de peixes na Aldeia, no entanto ainda não conseguiu firmar a parceria com o Estado para construção. Para a realização da pesca o método também é hibrido, os indígenas utilizam os conhecimentos tradicionais e realizam a pesca com isca natural (minhoca), mas não constroem mais as armadilhas de outrora e utilizam linhas e anzóis comprados no comércio local.

No que diz respeito à criação de animais de pequeno porte, o processo se dá utilizando os conhecimentos tradicionais. Um exemplo é que os indígenas usam uma planta para combater os vermes dos leitões que criam soltos pastando no terreno, trancando-os somente durante a noite em uma encerra.

Devido à pequena extensão territorial muitos dos materiais utilizados na fabricação dos artesanatos são colhidos fora do espaço da Aldeia. Neste caso, para garantir o artesanato, os indígenas precisam buscar insumos em outros espaços mais afastados. As taquaras e os cipós são coletados de acordo com as fases da Lua, pois, para eles, respeitando os ciclos da natureza esses materiais não serão extintos. As taquaras servem para fabricação de balaios, cestos, arcos e flechas; os cipós são usados para fabricação de filtros dos sonhos, ninhos de pássaros. Para confeccionar arcos e flechas também utilizam as madeiras da árvore guajuvira. As sementes, que os indígenas utilizam para confeccionar os colares e pulseiras, vêm de Santa Catariana. As tinturas para pintar os balaios, as linhas para trançar pulseiras e tornozeleiras, as plumas para enfeitar os filtros dos sonhos e os arcos e as flechas são comprados no comércio local ou importadas de São Paulo. Para confeccionar os filtros dos sonhos os kaingangs também utilizam materiais de plásticos reciclado. Deste modo, os kaingangs usam tanto produtos extraídos da natureza quanto os industrializados para confeccionar e dar acabamento aos seus artesanatos.

Entre as famílias indígenas kaingang que produzem os artesanatos na Aldeia Gyró, algumas comercializam diariamente no centro de Pelotas e outras apenas em datas comemorativas, como Páscoa e Natal. No verão, todas as famílias kaingangs da Aldeia Gyró, como tradicionalmente acontece em outros territórios, viajam para o litoral para comercializar os artesanatos nas praias. Alguns indígenas fazem viagens mais curtas até as praias próximas de Pelotas e outros realizam deslocamentos mais distantes, para outros Estados. Tanto a produção dos artesanatos como o lucro da venda dos produtos não são coletivos, mas, como vivem em coletividade os indígenas kaingang ajudam-se mutuamente uns aos outros no decorrer do ano.

Os indígenas kaingang da Aldeia Gyró preservam o meio ambiente e têm uma ligação forte com a natureza. Na semana que antecede o Dia do Índio -19 de abril - realizam um encontro, chamado Semana Cultural da Aldeia Gyró. Neste encontro os kaingangs mostram ao público as comidas típicas (fuá, farofa, pisé, etc.), as danças tradicionais, as pinturas corporais, as armadi- 
Ihas que eram utilizadas para caça, comercializam os artesanatos e fazem palestras explicativas dos seus costumes.

Na perspectiva de preservar os saberes e práticas, os indígenas utilizam recursos de audiovisual para transmitir documentários gravados em outras aldeias que explicam a cosmologia kaingang. Tal cosmologia é importante ferramenta de resistência ao modelo hegemônico, uma vez que envolve o cuidado com o meio ambiente e a vida em harmonia com a natureza.

Um fator que impede a reprodução das tecnologias sociais na Aldeia Gyró é o espaço territorial reduzido. A vida da forma originária não parece mais possível, pois está atravessada pela aproximação de ferramentas tecnológicas, científicas, ocidentais, como o telefone celular, a Internet, as redes sociais como o WhatsApp, etc., no entanto parece que os indígenas usam estas ferramentas de forma a garantir seus interesses diante da lógica dominante.

Com o intuito de fomentar e preservar a cultura indígena, os kaingangs estão num processo de disputa e possível conquista de um espaço, que se localiza em frente ao território onde estão construídas as casas de madeira de Aldeia Gyró. Nesse espaço, depois de regularizado, os indígenas pretendem construir um centro cultural kaingang, que contará com um museu indígena, apresentações artísticas, oficinas e palestras abertas dos kaingangs para a comunidade pelotense. Esse território, no entanto, abriga alguns colonos, situação que vem gerando alguns atritos com os lindeiros da Aldeia Gyró.

Uma das práticas ancestrais mantidas na Aldeia é a vida em comunidade. Nestas condições a transferência de saberes se dá no cotidiano da comunidade. Durante o andamento da pesquisa empírica alguns diálogos com os interlocutores kaingang ocorreram à sombra das árvores situadas no fundo da Aldeia Gyró. Observou-se que as crianças da Aldeia conversavam, brincavam livres no território, em outros momentos, quando despertava o interesse de trabaIhar na confecção de artesanatos, utilizavam as ferramentas dos adultos para falquejar as taquaras. $O$ jovem kaingang, artesão, que foi um dos interlocutores da pesquisa, revelou que as crianças têm interesse em trabalhar com artesanatos, acompanhando os pais nas atividades laborais de confecção das peças e, seguindo as orientações, aprendem a dar forma à madeira, aos cipós, etc. Assim, harmoniosamente é provável continuem o trabalho realizado pelos adultos.

Sobre o processo de gestão da Aldeia, existe todo um respeito à hierarquia estabelecida pelos indígenas, mas há também uma gestão dialógica. Pode-se observar que os diálogos influenciam nas decisões políticas da Aldeia Gyró e também servem para preservar as histórias dos kaingangs e a identificação ancestral com o território que eles ocupam. ${ }^{15}$

A questão da organização econômica dos indígenas kaingang - da produção até a comercialização dos artesanatos - envolve um processo dialógico, por meio de uma assembleia, ocasião em que eles decidem sobre o destino que a comunidade deve dar aos recursos monetários colhidos. Trata-se de um processo de reciprocidade. Como revela Luciane Lucas dos Santos (2017):

\footnotetext{
${ }^{15} \mathrm{Em}$ uma das oportunidades de encontro com o cacique, ele contou a história daquele território que estão ocupando e que constitui a cidade de Pelotas. Segundo o cacique, no passado distante, antes da colonização europeia, aquele território foi um local de encontro e celebração dos grupos indígenas kaingang que por ali passavam.
} 
Isso significa que a economia se organiza em função da reciprocidade, entendida como um valor social norteador (não só na relação entre os homens, mas também na relação entre eles e a natureza), nunca ao contrário (p. 29).

Desse modo, percebe-se que o processo econômico que envolve a Aldeia Gyró é bastante desafiador. Ao mesmo tempo que busca preservar as tradições e impõe uma dinâmica de produzir, respeitosa e não extrativista com a natureza, ainda assim, por vezes, reproduz a lógica dominante. O espaço territorial da Aldeia Gyró ficou reduzido a pouco mais de sete hectares, dificultando as condições produtivas dos indígenas com a terra e as águas. $O$ sustento dos indígenas kaingang da Aldeia Gyrós, portanto, restringe-se a uma pequena lavoura, à criação de animais de pequeno porte (que no máximo permite o consumo de uma família), à venda dos artesanatos produzidos na Aldeia e aos programas sociais do Estado brasileiro.

Os indígenas kaingang não encontram na natureza do novo território as frutas, as caças e os peixes que alimentaram as gerações passadas. Alegam que o meio ambiente está envenenado pelo uso abusivo de agrotóxicos, utilizados nas plantações agrícolas dos agricultores da região e alertam para um desastre natural sem precedentes históricos devido à forma como o branco se relaciona com a natureza.

Por fim, destaca-se a importância de visibilizar as tecnologias sociais e os saberes tradicionais kaingang abarcados no trabalho da Aldeia Gyró, mesmo que estejam em processo de invisibilização e silenciamento. Os esforços dos indígenas em manter suas práticas, saberes e tradições, evitando adentrar na economia de mercado neoliberal indiscriminadamente, é uma forma de evitar um verdadeiro epistemicídeo dos saberes tradicionais indígenas em relação aos remédios do mato (ervas), à alimentação com plantas e raízes, aos ciclos da Lua para colheita dos cipós, taquaras, etc., processo de resistência, que envolve e impulsiona toda uma relação de cuidado e reciprocidade com a natureza. A sociedade e o mercado capitalista veem estas experiências de produzir e viver como periféricas, e, como sinaliza Acselrad, "As demonstrações de reprodutibilidade autorregulada de comunidades tradicionais são repelidas pelo pensamento desenvolvimentista, que nelas vê sinais de regressismo, idealização do atraso e da pobreza" (ACSELRAD, 2018, p. 152).

\section{CONSIDERAÇÕES FINAIS}

A complexa relação, que varia do preconceito racial, da negação dos sabres, da negação dos direitos coletivos dos povos indígenas, da tomada dos territórios originais dos indígenas até o preconceito religioso, são relações sociais que estão marcadas desde o primeiro contato do colono "ocidental" com os indígenas americanos, como sinaliza Silva (2017, p. 20), "deixando vivo, nesse processo, que o detentor de todo o poder seria o homem branco retentor do conhecimento soberano (...)". Esta relação está presente na comunidade indígena kaingang em Pelotas.

Desde que estabeleceram a Aldeia Gyró em um território rural de Pelotas, os indígenas encontram muitas dificuldades de acesso às mínimas condições de subsistência. Enfrentam a ausência de terra e água suficientes para plantar, caçar e pescar; ausência de espaços para preservação da cultura, como o museu e a escola bilíngue; ausência de condições para comercia- 
lizar o artesanato, tendo em vista o alto custo do transporte até Pelotas; carência de políticas públicas em atenção à saúde, educação e assistência indígena.

Essas dificuldades colocam os indígenas em situações absolutamente periféricas na sociedade pelotense. Muitos deles já se dispõem a integrar o mercado formal de trabalho, mas não conseguem espaço, optando muitas vezes pelo trabalho informal, como vender balas no centro da cidade. Darcy Ribeiro já dizia que o espaço social destinado aos povos tradicionais, após a abolição da escravatura, é periférico.

Assim os contingentes negros e indígenas que tiveram de enfrentar enormes obstáculos para ascender da condição de escravos à de proletário concentram-se principalmente nas camadas mais pobres da população (RIBEIRO, 2010, p. 37).

O processo de negação dos direitos indígenas pelo Estado brasileiro ainda está presente nas relações sociais, mesmo após cinco séculos do começo da colonização. Isto pode ser comprovado na pequena fração de terra destinada ao assentamento dos indígenas kaingang em Pelotas, no qual as 16 famílias estão distribuídas em pouco mais de 7 hectares.

Sem condições de subsistência, os indígenas não conseguem reproduzir suas práticas e saberes e produzir tecnologias sociais adequadas ao seu modo de vida tradicional. Ainda assim, percebe-se os esforços dos indígenas em preservarem alguns saberes tradicionais no cotidiano da vida em comunidades. Estes saberes mesclam-se com os conhecimentos ocidentais, muitas vezes gerando tecnologias sociais hibridas.

A ausência de políticas públicas e a imposição das formas de organização pelo modo de produção capitalista, apesar da resistência dos kaingang, podem interferir no cotidiano da Aldeia Gyró, em que a organização coletiva dos indígenas para o trabalho representa uma lógica inversa ao capitalismo que procura individualizar as relações sociais e laborais, e assim, mudar a representações sociais dos indígenas a respeito da organização da vida. Por isso, é de suma importância visibilizar as tecnologias sociais e os saberes tradicionais abarcados no trabalho da Aldeia Gyró antes que ocorra, impulsionado pela economia de mercado neoliberal, um epistemicídeo dos saberes tradicionais indígenas. É difícil. Parece que a maioria das circunstâncias favorece tal epsitemicídeo, mas, da forma como é possível, os kaingangs da Aldeia Gyró vêm resistindo e se ressignificando diante das adversidades.

\section{REFERÊNCIAS}

ADDOR, Felipe. Teoria democracia e poder popular na América Latina: contribuição a partir das experiências de Cotacachi/Equador e Torres/Venezuela. Florianópolis: Insular, 2016.

ACSELRAD, Henri. O desenvolvimento entre tecnologia e história. In: HENRIQUE, Flávio Cheidid et al. (org.). Tecnologias para o desenvolvimento social: diálogos Nides - UFRJ. Marília: Lutas Anticapital, 2018. BRASIL. Constituição da República Federativa do Brasil: D.O. 5 de outubro de 1988. Disponível em: https://www.senado.gov.br/atividade/const/con1988/CON1988_05.10.1988/CON1988.pdf. Acesso em: 30 nov. 2017.

BRASIL. Decreto no 5.051, de 19 de abril de 2004. Promulga a Convenção no 169 da Organização Internacional do Trabalho - OIT sobre Povos Indígenas e Tribais. Disponível em: http://www.planalto.gov.br/ ccivil_03/_Ato2004-2006/2004/Decreto/D5051.htm. Acesso em: 10 nov. 2017.

BRASIL. Lei no 6.001, de 19 de dezembro de 1973. Dispõe sobre o Estatuto do Índio. Disponível em: http:// www.planalto.gov.br/ccivil_03/leis/L6001.htm. Acesso em: 14 nov. 2017.

CASTRO, Eduardo Viveiros. O mármore e a murta: sobre a inconcistância da alma selvagem. Revista de Antropologia, São Paulo: USP, v. 35, p. 21-74, 1992. 
CÉSAIRE, Aime. Discurso sobre o colonialismo. 1. ed. Lisboa: Livraria Sá da Costa, 1978.

CIMI. Conselho Indigenista Missionário. Relatório Cimi: violência contra os povos indígenas no Brasil tem aumento sistêmico e contínuo. Disponível em: https://cimi.org.br/2018/09/relatorio-cimi-violencia-contra-os-povos-indigenas-no-brasil-tem-aumento-sistemico-e-continuo/. Acesso em: 19 fev. 2019.

CLASTRES, Pierre. A sociedade contra o Estado (investigações de antropologia política). Porto: Afrontamento, 1979.

CUNHA, Gabriela; SANTOS, Aline Mendonça. Economia solidária e pesquisa em ciências sociais: desafios epistemológicos e metodológicos. In: HESPANHA, Pedro; SANTOS, Aline Mendonça (org.). Economia solidária: questões teóricas e epistemológicas. Coimbra: Almedina, 2010.

DaMATTA, Roberto. A casa \& a rua. 5. ed. Rio de Janeiro: Rocco, 1997.

DUSSEL, Enrique. 1492: o encobrimento do outro: a origem do mito da modernidade: Conferência de Frankfurt. Tradução Jaime A. Clasen. Petrópolis: Vozes, 1993.

FANON, Frantz. Os condenados da terra. Rio de Janeiro: Civilização Brasileira, 1968.

FERNANDES, Florestan. Capitalismo dependente e classes sociais na América Latina. Rio de Janeiro: Zahar, 1973.

FERNANDES, Ricardo Cid; PIOVEZANA, Leonel. Perspectivas Kaingang sobre o direito territorial e ambiental no sul do Brasil. Ambiente \& Sociedade, São Paulo v. XVII, n. 2, p. 132-155, abr./jun. 2015.

FREITAS, Elisa de Castro; ROKÀG, Francisco do Santos. O Kujà e o sistema de medicina tradicional Kaingang - "por uma política do respeito": Relatório do II Encontro dos Kujà, Terra Indígena Kaingang Morro do Osso. Cadernos do LEPAARQ - Textos de Antropologia, Arqueologia e Patrimônio, Pelotas, RS: Editora da Ufpel, v. IV, n. 7/8, ago./dez. 2007.

FUNAI. Museu do Índio. Mito e cosmologia. Disponível em: http://www.museudoindio.gov.br/educativo/ pesquisa-escolar/245-mito-e-cosmologia. Acesso em: mar. 2019.

GALEANO, Eduardo. Bolivia de pie nunca de rodillas, el país que quiere existir. Disponível em: https:// www.voltairenet.org/article120555.html. Acesso em: 2 mar. 2019.

ITS BRASIL. Instituto de Tecnologia Social. O que é tecnologia social. ITS BRASIL. Disponível em: http:// itsbrasil.org.br/conheca/tecnologia-social/. Acesso em: 9 abr. 2019.

LANDER, Edgardo (org.). A colonialidade do saber: eurocentrismo e ciências sociais. Buenos Aires, Argentina: Clacso, 2005. Disponível em: http://www.antropologias.org/rpc/files/downloads/2010/08/Edgardo-Lander-org-A Colonialidade-do-Saber-eurocentrismo-e-ci\%C3\%AAncias-sociaisperspectivaslatinoamericanas-LIVRO.pdf. Acesso em: 30 nov. 2017.

LAROQUE, Luís Fernado da Silva; SILVA, Juciane Beatriz Sehn da. Ambiente e cultura Kaingang: saúde e educação na pauta das lutas e conquistas dos Kaingang de uma terra indígena. In: Educação em Revista, Belo Horizonte, v. 29, n. 2, p. 253-275, jun. 2013. Disponível em: http://www.scielo.br/scielo.php?pi$\mathrm{d}=$ S010246982013000200011\&script=sci_abstract\&tlng=pt. Acesso em: 19 out. 2017.

MARICATO, Erminia. O impasse da política urbana no Brasil. 3. ed. Petrópolis, RJ: Vozes, 2014.

MBEMBE, Achile. Biopoder; soberania; estado de exceção; política da morte. Arte \& Ensaio. Revista do PPGAV/EBA/UFRJ, n. 32, dez. 2016.

MINAYO, Maria Cecília de Souza (org.). Pesquisa social: teoria, método e criatividade. 30. ed. Petrópolis, RJ: Vozes, 2011.

NOVAES, Henrique Tahan. O fetiche da tecnologia: a experiência das fábricas recuperadas. 2. ed. São Paulo: Expressão Popular, 2010.

NOVAES, Henrique Tahan. Por uma teoria crítica da tecnociência e pela urgência de uma sociedade além do capital. In: HENRIQUE, Flávio Cheidid et al. (org.). Tecnologias para o desenvolvimento social: diálogos Nides - UFRJ. Marília: Lutas Anticapital, 2018.

NIETZCHE, Friedrich Wilhelm. Genealogia da moral: uma polêmica. São Paulo: Companhia das Letras, 2009.

PORTO GONÇALVES, Carlos Walter. De saberes e de territórios - diversidade e emancipação a partir da experiência latino-americana. In: HENRIQUE, Flávio Cheidid et al. (org.). Tecnologias para o desenvolvimento social: diálogos Nides - UFRJ. Marília: Lutas Anticapital, 2018.

PRADO JÚNIOR, Caio. História econômica do Brasil. São Paulo: Brasilense, 2006.

QUIJANO, Anibal. A colonialidade do saber: eurocentrismo e ciências sociais. Buenos Aires. Clacso, 2005. RIBEIRO, Darcy. A América Latina existe? Apresentação Eric Nepomuceno. Rio de Janeiro: Fundação Darcy Ribeiro; Brasília: Ed. UnB, 2010. 
ROSA, Michel Fernandes. Os atingidos de Belo Monte: experiências de sofrimento e agravos à saúde no contexto de um megaprojeto hidroelétrico na Amazônia brasileira. 2016. Tese (Doutorado em Sociologia) - Faculdade de Economia da Universidade de Coimbra, Coimbra, Portugal, 2016. Orientação professor doutor João Arriscado Nunes.

ROSA, Rogério Reus Gonçalves. "Os Kujà são diferentes": um estudo etnológico do complexo xamânico dos Kaingang da terra indígena Votouro. 2005. 416 f. Tese (Doutorado em Antropologia Social) - Universidade Federal do Rio Grande do Sul, Porto Alegre, 2005.

ROSA, Rogério Reus Gonçalves. Os Kujà são diferentes? Doenças invisíveis, aliança e guerra no Xamanismo Kaingang. Rev. Mediações, Londrina, v. 19, n. 2, p. 84-110, jul./dez. 2014.

SANTOS, Aline Mendonça dos. As outras economias no marco das epistemologias do Sul. In: GAIGER, Luiz Inácio Germany; SANTOS, Aline Mendonça dos (org.). Solidariedade e ação coletiva: trajetórias e experiências. São Leopoldo: Editora Unisinos, 2017.

SANTOS, Boaventura de Sousa. A filosofia à venda, a douta ignorância e a aposta de Pascal. In: Revista Crítica de Ciências Sociais, 80, p. 11-43, mar. 2008.

SANTOS, Boaventura de Sousa. Entre o próspero e o Caliban: colonialismo, pós-colonialismo e interidentidade. In: RAMALHO, I.; RIBEIRO, A. S. (org.). Entre ser e estar: raízes, percursos e discursos da identidade. Porto: Afrontamento, 2001.

SANTOS, Luciane Lucas dos. Economias indígenas, cosmovisão e territorialidade: os qhathu no altiplano indígena. In: GAIGER, Luiz Inácio Germany; SANTOS, Aline Mendonça dos (org.). Solidariedade e ação coletiva: trajetórias e experiências. São Leopoldo: Editora Unisinos, 2017.

SANTOS, Milton. A natureza do espaço: técnica e tempo, razão e emoção. 4. ed. São Paulo: Editora da Universidade de São Paulo, 2006.

SANTOS, A. M.; RIBEIRO, C. J. La soberanía alimentaria y la economía solidaria como estrategias de la reforma agraria en Brasil. In: MICARELLI, Giovanna; JACOB, Luciana Buainain (org.). Soberanía alimentaria: prácticas y saberes locales para un movimiento global contrahegemónico. 1. ed. Bogotá: Editorial Pontificia Universidad Javeriana, 2020. p. 58-83. V. 1.

SEVERO, Diego Fernandes Dia. Xamanismo e mitologia Kaingang: elementos sobre a crença evangélica no pensamento ameríndio. Rev. Equatorial, Natal, v. 5, n. 8, jan./jun. 2018, p. 141-163.

SILVA, Sergio Baptista. Dualismo e cosmologia Kaingang: o Xamã e o domínio da floresta. Horizontes Antropológicos, Porto Alegre, a. 8, n. 18, p. 189-209, dez. 2002.

SILVA, Matheus da Silva e. Colonialismo, Estado e a invisibilidade dos povos indígenas no Brasil: um desafio para o Serviço Social. 2017. Trabalho (Conclusão de Curso) - Universidade Católica de Pelotas, Centro de Ciências Jurídicas Econômicas e Sociais, Pelotas, 2017.

TUPINAMBÁ, Anapuaka. Refletindo sobre povos tradicionais, raça e gênero na engenharia. In: HENRIQUE, Flávio Cheidid Henrique et al. (org.). Tecnologias para o desenvolvimento social: diálogos Nides - UFRJ. Marília: Lutas Anticapital, 2018.

VERONESE, Marília Verissimo; FERRARINI. A pesquisa sociopoética como método de tradução epistemológica. In: GAIGER, Luiz Inácio; SANTOS, Aline Mendonça (org.). Solidariedade e ação coletiva: trajetórias e experiências. São Leopoldo: Editora Unisinos, 2017. 